\title{
Trajetórias teórico-metodológicas em 10 anos de produção do GT 23 da Associação Nacional de Pós-Graduação e Pesquisa em Educação - ANPEd ${ }^{1}$
}

\author{
Cláudia Maria Ribeiro² \\ Constantina Xavier Filha ${ }^{3}$
}

\begin{abstract}
Resumo: O presente texto teve por objetivo analisar e problematizar os trabalhos apresentados no Grupo de Trabalho (GT 23) da Associação Nacional de Pós-Graduação e Pesquisa em Educação - ANPEd, em dez anos de existência. Os textos apresentados, oralmente e em formato de pôster, foram aqui subdivididos nos primeiros cinco anos e nos últimos cinco, para efeitos de análises. Observamos que a região Sudeste brasileira é a que concentra a maior produção de pesquisas nos campos teóricos das sexualidades e gênero na área da educação apresentada no GT. Há uma diversidade teórico-metodológica dos trabalhos apresentados, bem como de temáticas, público específico e fontes de análise. O GT, na sua década de existência, mostrou-se como um espaço profícuo de discussões, reflexões, encontros, socializações de saberes e potencialidades de novas pesquisas nos campos teóricos priorizados.
\end{abstract}

Palavras-Chave: Grupo de trabalho; Campos de pesquisas; Sexualidades; Gênero.

Abstract: The purpose of this paper was to analyse and discuss about presentations performed in the Working Group (WG 23) of the National Association of Postgraduate and Research in Education during 10 years of existence. Presentations of posters and orally performed were grouped in the first five, and in the last five years, for the intent of analysis. We found that the majority of studies about sexuality and gender, in the area of education presented in the WG, is concentrated in Southeast region of Brazil. There is a theoretical and methodological diversity of papers, as well as themes, specific target audience, and sources of analysis. During its decade of existence, the WG was found to be an useful space of discussions, reflections, meetings, socialization of knowledge, and potentiality of new researches in prioritized theoretical areas.

Key-words: Working group; Research areas; Sexuality; Gender.

Resumén: El presente texto ha tenido por objeto analizar y discutir los trabajos presentados en el Grupo de Trabajo (GT 23) de la Asociación Nacional de Postgraduación e Investigación - ANPEd en diez años de existencia. Los textos presentados, oralmente [y] en formato de póster, se han subdividido en los primeros cinco años y en los últimos cinco años, a los efectos de su análisis. Observamos que la región Sudeste brasileña es la que concentra la mayor producción de estudios en los campos teóricos de las sexualidades y género en el área de la educación presentada en el GT. Hay una diversidad teórico-metodológica de los trabajos presentados, así como de temáticas, público específico o fuentes de análisis. El GT en su década de existencia se ha mostrado como un espacio fructífero de discusiones, reflexiones, encuentros, socializaciones de conocimientos y potencialidades de nuevas investigaciones en los campos teóricos priorizados.

Palabras clave: Grupo de trabajo; Campos de investigaciones; Sexualidades; Género.

1 Texto com modificações do Trabalho Encomendado apresentado no GT 23 da ANPEd, na $36^{\text {a }}$. Reunião Nacional realizada em Goiânia, 2013.

2 Profa. Associada do Departamento de Educação da Universidade Federal de Lavras - MG. Coordenadora do Grupo de Pesquisa: Relações entre filosofia e educação para a sexualidade na contemporaneidade: a problemática da formação docente - FESEX. Pós-doutora na Universidade do Minho - Braga, Portugal.

3 Profa. Associada da Unidade de Educação do CCHS - da Universidade Federal de Mato Grosso do Sul - UFMS. Coordenadora do GEPSEX - Grupo de Estudos e Pesquisas em Sexualidades, Educação e Gênero. Coordenadora do GT 23 - ANPEd (Gestões 2012 a 2015). 


\title{
1. INÍCIO DE NOSSAS TRAJETÓRIAS...
}

\begin{abstract}
Como se fora brincadeira de roda, memória. Jogo do trabalho na dança das mãos, macias. O suor dos corpos na canção da vida, história. O suor da vida no calor de irmãos, magia.
\end{abstract} Gonzaguinha

10 anos! Quanta história! Quanta memória! Quantas pessoas deram-se as mãos, de diferentes maneiras, suando seus corpos para implantar e implementar o Grupo de Trabalho (GT) 23. A memória remete ao ano de 2003, durante a $26^{\mathrm{a}}$ Reunião Anual (RA) da ANPEd, realizada em Poços de Caldas - MG, em que um grupo de pesquisadoras/es, docentes e estudantes, mobilizouse para propor à Associação a criação de um Grupo de Estudos que se voltasse para as temáticas de gênero e sexualidade em sua articulação com a educação. Muito suor para que - de GT em GT - nas distâncias dos hotéis naquela cidade, conseguíssemos a adesão de 500 assinaturas. A proposta foi encaminhada à Assembleia Geral daquela RA e aprovada. Criava-se, assim, o Grupo de Estudos (GE) 23 Gênero, Sexualidade e Educação. A rede de estudiosas/os e pesquisadores/as que, há vários anos, ensaiava contatos no âmbito da ANPEd conquistava um espaço privilegiado.

Os muitos grupos e núcleos de pesquisa ligados aos estudos de gênero, de sexualidade e de educação para a sexualidade, existentes nas instituições de educação superior e nos programas de pós-graduação do país, dispersos e distantes uns dos outros, passavam a ter o GE 23 como um ponto de referência; aqueles pesquisadoras/es e estudantes que, muitas vezes isoladamente, desenvolviam investigações ou práticas pedagógicas focadas nessas temáticas eram estimulados/ as a buscar na ANPEd, parceiras/os para o diálogo e para o debate teórico. Espaço legitimado no interior da mais importante associação brasileira de educação, para constituir uma rede que ampliasse as possibilidades para as visibilidades e para o fortalecimento do campo marcando uma consolidação acadêmica e política.

A pluralidade teórico-metodológica e a constante autocrítica que têm acompanhado a produção de conhecimento nos estudos de gênero e sexualidade foram ressaltadas por colegas que abriam as discussões do GE e logo se mostrariam evidentes nas exposições e debates. Aqui contemplou-se extratos do texto veiculado na página da internet ${ }^{4}$ apresentado à Assembleia Geral da ANPEd com a proposição de transformação de GE em Grupo de Trabalho, no ano de 2005. As partes do referido texto são retomadas pela sua força histórica ressaltando a importância da constituição do espaço Gênero, Sexualidade e Educação na ANPEd.

Nesses 10 anos de existência do GT 23 foram inventadas modalidades de relações, formas de troca entre as pessoas, tanto integrantes do GT quanto em sua relação com a Associação, para potencializar a canção da vida e o calor de irmãos/ãs que traduzimos como as possibilidades da tessitura de outro tecido relacional, navegando entre as capturas, as relações de poder e a força criativa da amizade:

4 Texto completo disponível em www.ded.ufla.br/gt23 e www.anped.org.br (GT 23). 
A amizade [...] é a afirmação de existências livres. Os amigos vivem pelas suas diferenças. Não são espelhos para os outros, identidade coletiva ou ideal, fusão numa unidade superior. Os amigos livres são seus principais inimigos, não deixam as coisas sossegadas, como se houvesse um patamar acima a ser atingido onde residem o equilíbrio, a doçura e as delicadezas obrigatórias. (PASSETTI, 2003, p. 12)

O autor fala da amizade em Foucault e o quanto ela está inundada de conflitos, experimentações, reflexões, trabalhos, suores, danças, diferenças que inquietam e que potencializam a liberdade necessária para transitar nas relações de poder; para a construção de outro tecido relacional que fortaleça as pessoas para os embates cotidianos - políticos, éticos, sociais. Nessa tessitura, nesses 10 anos, quanto conhecimento produzido, apresentado e veiculado nas Reuniões Anuais da Associação. Quanta possibilidade de interferir em processos educativos de formação inicial e continuada de educadores e educadoras a partir dos estudos do material produzido, quantas possibilidades de novas proposições de estudos, provocações, problematizações e desejo de navegarmos por mares revoltos e instáveis do conhecimento.

\section{Os 10 anos de produção teórico-metodológica}

Este artigo tem por objetivo mapear e esboçar uma análise dos trabalhos (apresentação oral e pôster) apresentados ${ }^{5}$ no decorrer dos anos da $27^{\mathrm{a}}$. à $36^{\mathrm{a}}$. RA (de 2004 a 2013). Fez-se o download de todos os trabalhos e pôsteres dos 10 anos contemplando o seguinte procedimento: separou-se cada reunião em uma pasta de arquivo no computador; efetuou-se a leitura individual e completa de cada trabalho e pôster com vistas a mapear os autores e as autoras, as instituições e região de origem, a temática dos trabalhos, o referencial teórico e se havia financiamento ou não. Produziram-se tabelas, por Reunião Anual (RA), fazendo-se, também, uma síntese de cada trabalho e pôster anotando os aspectos significativos tanto para a construção de uma tabela final quanto para problematizações em torno das temáticas e referenciais teóricos abordados. Abaixo a tabela 1 com os dados gerais de todos os trabalhos analisados.

Tabela 1 - Trabalhos e Pôsteres do GT 23 (10 anos)

\begin{tabular}{|c|c|c|c|c|c|}
\hline \multirow[t]{2}{*}{ ANO } & \multirow[t]{2}{*}{ GE/GT } & \multirow[t]{2}{*}{ REUNIÃO } & \multirow[t]{2}{*}{ LOCAL } & \multicolumn{2}{|c|}{$\begin{array}{l}\text { TRABALHO APROVADO/ } \\
\text { APRESENTADO }\end{array}$} \\
\hline & & & & $\begin{array}{c}\text { Trabalho - } \\
\text { Apresentacão Oral }\end{array}$ & Pôster \\
\hline 2004 & GE & $27^{a}$ & Caxambu/MG & 13 & 05 \\
\hline 2005 & GE & $28^{\mathrm{a}}$ & Caxambu/MG & 13 & 08 \\
\hline 2006 & GT & $29^{a}$ & Caxambu/MG & 12 & 04 \\
\hline 2007 & GT & $30^{a}$ & Caxambu/MG & 16 & 01 \\
\hline 2008 & GT & $31^{\mathrm{a}}$ & Caxambu/MG & 11 & 03 \\
\hline 2009 & GT & $32^{\mathrm{a}}$ & Caxambu/MG & 12 & 02 \\
\hline 2010 & GT & $33^{\mathrm{a}}$ & Caxambu/MG & 15 & 03 \\
\hline 2011 & GT & $34^{\mathrm{a}}$ & Natal/RN & 15 & 00 \\
\hline 2012 & GT & $35^{\mathrm{a}}$ & Porto de Galinhas/PE & 17 & 03 \\
\hline 2013 & GT & $36^{\mathrm{a}}$ & Goiânia/GO & 17 & 02 \\
\hline & & & TOTAL & 141 & 31 \\
\hline \multicolumn{4}{|c|}{ TOTAL GERAL (Trabalho e Pôster) } & \multicolumn{2}{|r|}{172} \\
\hline
\end{tabular}

Fonte: Trabalhos apresentados no GT 23 - Site da ANPEd

5 Analisamos os trabalhos dispostos em cada uma das Reuniões Anuais no site da Anped, dentre eles os excedentes que, no caso, não foram apresentados mas aprovados e publicados nos Anais e site da Anped. 
Observamos que há uma regularidade de trabalhos apresentados no GT 23, inclusive com a seleção de trabalhos como excedentes, revelando com isso a consolidação do grupo ao longo dos seus dez anos de existência com a apresentação e discussão de estudos e pesquisas relevantes e que incitam a novos estudos. Outro aspecto analisado refere-se a região de origem dos trabalhos apresentados. Essa organização foi feita dividida em dois períodos, a primeira (Tabela 2) dos primeiros cinco anos de trabalhos apresentados no GT e a segunda (Tabela 3) com os dos últimos cinco anos.

Tabela 2 - Região de Origem dos trabalhos/pôsteres apresentados no GT 23 - 2004-2008

\begin{tabular}{|c|c|c|c|}
\hline \multicolumn{4}{|c|}{ Região de origem - Trabalhos GT 23 - 2004 a 2008} \\
\hline Região & Trabalho & Pôster & Total \\
\hline Sudeste & 36 & 18 & 54 \\
\hline Sul & 23 & 3 & 26 \\
\hline Nordeste & 5 & $\mathbf{0}$ & 5 \\
\hline Centro-Oeste & 1 & $\mathbf{0}$ & 1 \\
\hline Norte & 0 & 0 & 0 \\
\hline Total & 65 & 21 & 86 \\
\hline
\end{tabular}

Fonte: Trabalhos apresentados no GT 23 - Site da ANPEd

Tabela 3 - Região de Origem dos trabalhos/pôsteres apresentados no GT 23 - 2009-2013

\begin{tabular}{|l|r|r|r|}
\hline \multicolumn{2}{|c|}{ Região - Trabalhos GT 23 2008 a 2013} \\
\hline Região & Trabalho & Pôster & Total \\
\hline Sudeste & 30 & 6 & 36 \\
\hline Centro-Oeste & 32 & 1 & 33 \\
\hline Norte & 4 & 2 & 6 \\
\hline Nordeste & 3 & 0 & 3 \\
\hline Centro-Oeste e Sudeste & 3 & 1 & 4 \\
\hline Nordeste e Sudeste & 1 & 0 & 1 \\
\hline Não consta & 1 & 0 & 1 \\
\hline Total & 2 & 0 & $\mathbf{0}$ \\
\hline
\end{tabular}

Fonte: Trabalhos apresentados no GT 23 - Site da ANPEd

Profissionais da região Sudeste inscreveram e aprovaram a maioria dos trabalhos e pôsteres apresentados ao longo desses 10 anos. Muitos questionamentos poderiam ser feitos em relação a ausência das regiões Norte, Nordeste e Centro-Oeste. Distância? Dificuldades de financiamento? Apresentação dos trabalhos nas reuniões científicas regionais? Quanto ao financiamento ${ }^{6}$, a partir da $29^{\text {a }}$. RA há aumento de trabalhos financiados apresentados.

Passaremos a seguir para a descrição e análise dos trabalhos e pôsteres apresentados/selecionados no GT 23. Nossa escrita está dividida em dois blocos; no primeiro com o detalhamento de cada uma das cinco primeiras RAs. No segundo, com a discussão sobre os trabalhos apresentados nos

6 Não foi possível obter essa informação de todos os trabalhos devido a inexistência desses dados no site em algumas RAs. 
últimos cinco anos do GT 23, buscando proximidades, distanciamentos, silenciamentos... entre todos os apresentados/selecionados?

\section{3) Produções e saberes dos trabalhos nos primeiros cinco anos de existência do GT 23}

\section{1) $27^{\mathrm{a}}$. RA - a primeira reunião do Grupo de Estudos 23}

Iniciaremos pelos pôsteres. Dos 5 apresentados, 4 remetem à educação para a sexualidade ${ }^{8}$ no cotidiano escolar - nenhum utiliza essa nomenclatura havendo a preferência para a terminologia orientação sexual ou educação sexual. Os trabalhos abordam as seguintes temáticas: a) a homossexualidade no cotidiano escolar em relação à discriminação, violência e resistências; b) orientação sexual na escola e os limites e possibilidades da efetivação de um projeto com crianças de $4^{\text {a }}$ série do Ensino Fundamental; c) proposta de ação resultante da análise sócio-educativa com jovens na temática da saúde reprodutiva; d) significados de gênero para meninos e meninas de $4^{\mathrm{a}}$ série do Ensino Fundamental. O outro tema refere-se a pesquisa de como as mulheres deixam suas marcas nos bordados. Apenas um trabalho informa que teve financiamento e é decorrente das análises do material empírico da pesquisa de campo realizada no mestrado, em continuidade no doutorado. As metodologias consistem nas observações de campo, entrevistas semiestruturadas e etnografias. As pesquisas apresentadas revelam seu caráter de intervenção no cotidiano escolar considerando a produção de conhecimento comprometido com as políticas educacionais e as possibilidades de transformação.

Os trabalhos, em número de 13, veiculam a diversidade dos temas possíveis tanto para as sexualidades quanto para as relações de gênero e, muitas vezes, entrelaçam-se: 1) práticas discursivas que produzem a identidade de profissionais da educação em uma série de vídeos educativos do Ministério da Saúde - DST/AIDs; 2) a produção e reprodução da homossexualidade no ambiente escolar; 3) sexualidade adolescente; 4) análise de filmes dos estúdios Disney; 5) seleção de passagens da Bíblia para ilustrar a permanência do discurso bíblico no inconsciente coletivo das mulheres professoras; 6) fracasso e sucesso escolar de meninos e meninas nas séries iniciais; 7) relações de gênero no Ensino Fundamental; 8) análise de revistas nacionais do segmento editorial com a temática da infância; 9) experiências masculinas na carreira administrativa no Estado de São Paulo (1950-1980); 10) representações de gênero entre sindicalistas; 11) gênero e futebol feminino; 12) proposta de ação socioeducativa na temática da gravidez na adolescência; 13) interações de mulheres educadoras com imagens cinematográficas.

Para o acesso ao material empírico, os instrumentos de pesquisa foram: observação, textos produzidos no âmbito da pesquisa, análise de proposta de ação, entrevistas, questionários, seleção de artigos de revistas, de filmes, de trechos da Bíblia e diários de campo. A maioria dos textos circunscrevem as

7 No decorrer de nossas análises, não realizaremos as devidas referências a todos os inúmeros trabalhos destacados somente os que citamos ao longo do texto.

8 Ver conceito em XAVIER FILHA, Constantina. Educação para a sexualidade, para a equidade de gênero e para a diversidade sexual. Campo Grande, MS: Editora da UFMS, 2009. 
problematizações no referencial teórico de Michel Foucault, Joan Scott, Guacira Lopes Louro, Judith Butler, Nikolas Rose, Robert Connell e Stuart Hall. Alguns trabalhos assumem a perspectiva pósestruturalista de análise, os Estudos Culturais e Estudos de Gênero. Há esse anúncio generalizante e algumas aproximações entre os trabalhos são possíveis, outras não. A tônica das análises recai no olhar para os corpus analíticos como textos que constroem verdades e para as diferentes posições de sujeitos que apresentam seus enunciados. Poderíamos pensar com Foucault que os trabalhos apresentados possibilitam "criar uma história dos diferentes modos pelos quais, em nossa cultura, os seres humanos tornam-se sujeitos" (FOUCAULT, In RABINOW \& DREYFUS, 1995, p. 231). Outros conceitos deste autor transitam pelos trabalhos, a saber: população, biopoder, dispositivos de saber/poder, técnicas de normalização, disciplina. Há, portanto, citações deste autor, e muitos outros referenciais emergem e, alguns, na tentativa de interlocução, tais como Alberto Melucci, Bourdieu, dentre outros, nem sempre bem sucedidas, pois são sutilezas teóricas que diferenciam as concepções - algumas vezes apresentadas como semelhantes. Um único trabalho refere-se a Judith Butler que, baseando-se na Teoria dos Atos Performativos de John Austin, elabora essa teoria para Gênero e Sexualidade. Também, pela primeira vez, cita-se o autor Derrida, que deu origem ao conceito de citacionalidade na obra de Butler. Em outro trabalho há parágrafos inteiros sobre a performatividade e não remete à autoria do conceito. Outro aspecto que discutimos, pois nossa proposta para a escrita deste artigo é levantar questionamentos que consideramos interessantes para problematizações e não realizar classificações, foi o fato de que trabalhos advindos de uma mesma instituição trazem contribuições teóricas específicas como os estudos de gênero a partir da perspectiva de Robert Connell ou mesmo um levantamento de pesquisas sobre Educação e Relações de Gênero em obras latino americanas - inclusive brasileiras - e francesas. Devido a especificidade de trabalhos resultantes de processos históricos, outras pesquisas da mesma natureza foram também apresentadas, o que ampliou sobremaneira a discussão do artigo. A maioria dos trabalhos remete às contribuições para a Educação contemplando problematizações que atravessam os processos educativos na Escola.

\section{2) 28. RA - cumprindo o "estágio probatório" para transformação em GT}

Esta foi a RA na qual mais pôsteres foram apresentados - em número de 8 -, durante todos os dez anos. Nesse movimento que imprimimos ao texto: perguntas geradoras de perguntas e não com o intuito das classificações, seguimos nossa viagem pelas produções: 2 trabalhos financiados e um deles decorrente de verba para projetos de extensão, o que anuncia a possibilidade de articulação com a pesquisa. Os temas foram diversos, a saber: 1) práticas cotidianas articuladas ao bordado; 2) violência sexual contra crianças e adolescentes; 3 ) gênero, raça e etnia na formação docente; 4) desempenho das mulheres no indicador nacional de alfabetismo funcional; 5) práticas de gênero e sexualidade nas concepções de alunas/os do Ensino Médio; 6) aids na infância; 7) gênero na prática pedagógica da Educação Infantil; 8) sexualidade, infância e adolescência.

Os trabalhos foram em número de 13 e são decorrentes de estudos etnográficos, entrevistas semiestruturadas, observações, fonte documental, depoimentos, registros iconográficos, buscas em páginas brasileiras na internet, grupos de discussão, grupos focais, questionários - para navegar entre 
diferentes temas: 1) apropriação de personagens de novelas por adolescentes de camadas populares; 2) monstruosidades no currículo da Educação Sexual; 3) apropriação de novas tecnologias por docentes; 4) como a educação sexual é transmitida na escola; 5) desempenho escolar e gênero; 6) sexualidade e jovens do MST; 7) educação sexual no Brasil nos documentos da Inquisição (séculos XVI e XVII); 8) brinquedos e gênero; 9) construção da personagem Lara Croft; 10) aids na escola; 11) gênero e o uso dos tempos na escola; 12) sexualidades de pessoas deficientes; 13) gravidez na adolescência. Tantos temas, tantas possibilidades para problematizações, mas desta RA gostaríamos de pensar as possibilidades de interação da produção nos GTs e a formação de educadores e educadoras, tanto inicial quanto continuada. Pela facilidade de acesso à internet, nesses processos de formação, indica-se a leitura para discussão. Essa seria uma interessante investigação: onde, como e quando os textos aprovados no GT 23 são discutidos em outros espaços? Especialmente o texto de Jimena Furlani (2005), intitulado Sexos, sexualidades e gêneros - monstruosidades no currículo da Educação Sexual, tem mobilizado educadoras e educadores a refletirem a partir desse fenômeno metafórico cultural: "os monstros" (COHEN, 2000) - que fascinam e apavoram. Tem como referência a desconstrução (DERRIDA, 2001) como método analítico questionando a linguagem utilizada numa coleção de livros paradidáticos. O texto navega pela problematização dos binarismos, das certezas, do caráter construído das identidades culturais e da educação sexual marcada pela polêmica, pela provisoriedade e pela normatização. Que aproximações poderiam ser feitas deste texto e de outros apresentados nesta RA? Fundamentalmente porque a maioria deles remetem ou efetivam suas pesquisas no chão da escola e deparam com os medos e os fascínios em relação a Educação para a Sexualidade e os entraves para a implantação nas escolas de quaisquer níveis.

Assim, essa produção efetiva - complexa e profícua - embasou a proposição da passagem do Grupo de Estudos (GE) Gênero, Sexualidade e Educação para Grupo de Trabalho (GT) na ANPEd. E não só reportando-nos aos trabalhos e pôsteres, mas nesse movimento de consolidação acadêmica e política desse campo, reportando-nos também aos trabalhos encomendados, as participações nas Sessões Especiais, as Sessões Conversa, o trabalho do grupo de consultores e consultoras ad hoc, a representação do GE no Comitê Científico, o número representativo de diferentes instituições de ensino superior do país e a participação de membros do GE em reuniões científicas nacionais e internacionais.

\section{3) $29^{a}$. RA - primeiro ano de produção após alçar a condição de GT}

O número de pôsteres apresentados reduziu-se à metade. Alguns questionamentos: tempo de existência do GT para que as pessoas se organizassem para as suas produções de trabalhos completos? Valorização e visibilidade das exposições orais? Decidiu-se, a partir desta RA, que a apresentação do pôster seria feita também no espaço do GT e os temas foram os seguintes: 1) as mulheres e o futebol no cotidiano escolar; 2) alfabetização e as questões de gênero; 3 ) representações sociais de educadores/as do Ensino Fundamental sobre sexualidade e 4) representações de homens e mulheres acerca da maternidade. 
Os trabalhos foram em número de 12 e versaram sobre os seguintes temas: 1) grupos gays, educação e a constituição do sujeito homossexual; 2) (des)construção de corpos "deficientes"; 3) testes da imprensa feminina das décadas de 50 a 70 do século XX; 4) gênero e risco da HIV/Aids nas campanhas de educação em saúde; 5) juventude e pedagogias amorosas/sexuais; 6) gênero, educação e educação física na produção teórica brasileira; 7) violência sexual contra crianças e adolescentes; 8) a escrita que aparece nos bordados; 9) representações de gênero nos livros didáticos de matemática; 10) cinema, relações de gênero e mulheres idosas; 11) a homossexualidade no espaço escolar; 12) infâncias, adolescências e aids. Temas diversos evidenciando a amplitude de possibilidades para problematizar as relações de gênero e sexualidade. Qualquer fio que se puxasse de qualquer um desses trabalhos subsidiaria muitas discussões. Nossa opção foi focar a (des) construção dos corpos “deficientes” (CAMPOS, 2006). Há a informação de que este trabalho é parte da dissertação de mestrado da autora que anuncia o tabu de nossa sociedade em relação ao tema engalfinhado a expressão da sexualidade com rótulos que navegam entre as fronteiras de pessoas assexuadas a hipersexualizadas - anjos ou demônios. No decorrer das problematizações, a autora busca as contribuições de Ortega (2002) e alguns conceitos, tais como bioidentidade, autoperitagem, biossociabilidade, retórica do risco, prática ascética, bio-ascese, são discutidos. Poderíamos puxar outros fios, de outros trabalhos que abordam temas instigantes tais como as homossexualidades (FERRARI, 2006), mulheres idosas (FERNANDES e SIQUEIRA, 2006), as análises de anúncios televisivos de campanhas oficiais de risco de HIV/Aids (SANTOS e OLIVEIRA, 2006), violência sexual contra crianças e adolescentes (LIBÓRIO e CAMARGO, 2006), dentre outros.

\section{4) $30^{\mathrm{a}}$. RA: trabalhos aprovados e veiculados para além dos limites do GT}

Apenas um pôster, intitulado Abordagem do HPV na escola: caminhos e questionamentos no terceiro ano do Ensino Médio, foi apresentado. Consiste em uma pesquisa para avaliar o nível de conhecimento dos/das adolescentes sobre essa DST.

Já em relação aos trabalhos, esta RA foi a que contemplou, até agora, o maior número de trabalhos aprovados para apresentação e navegam pelos seguintes temas: 1) imprensa feminina e discursos de professoras; 2) banheiros escolares; 3) homossexualidades masculinas no contexto escolar; 4) professores homens na docência com crianças; 5) o jogo e as estratégias de gênero na alfabetização; 6) trajetória de vida de alunas egressas de um curso de pedagogia da década de 80; 7) desempenho escolar de meninos e meninas; 8) a boneca Barbie e a educação de meninas; 9) produção das mães nas páginas da revista Pais \& Filhos; 10) gênero e sexualidade nos PCNs; 11) sexualidade e o currículo de formação de professores e professoras; 12) obrigação no trabalho doméstico familiar de jovens estudantes; 13) gênero, sexualidade e bordado; 14) gênero e envelhecimento; 15) representações de sexualidade no curso normal noturno; 16) feminização da profissão docente na Educação Infantil.

Resolvemos puxar o fio dos trabalhos aprovados, apresentados e que receberam o convite para a participação no livro Tecendo gênero e diversidade sexual nas redes de proteção (RIBEIRO e SOUZA, 2008). O referido livro integrou o projeto do mesmo nome, aprovado pela SECAD, hoje 
SECADI - Secretaria de Educação Continuada, Alfabetização, Diversidade e Inclusão do Ministério da Educação - MEC, que objetivou realizar a formação de educadoras e educadores no sul de Minas Gerais e, para tanto, deveria produzir um livro que seria estudado com as pessoas integrantes do projeto. Houve, então, uma tiragem de 5.000 exemplares; os livros foram distribuídos para estudos e discutidos em processos de formação, contemplando metodologias específicas. Quanto subsídio teórico com a leitura e discussão dos textos: “O que é Loba??? É um jogo sinistro, só para quem for homem..." gênero e sexualidade no contexto escolar, de Anderson Ferrari (2008); Banheiros escolares - promotores de diferenças de gênero, de Adla Betsaida Martins Teixeira e Ana Elvira S. Silva Raposo (2008); A sexualidade feminina entre práticas divisoras: da mulher "bela adormecida" sexualmente à multiorgástica - imprensa feminina e discursos de professoras, de Constantina Xavier Filha (2008). $\mathrm{O}$ primeiro texto possibilitou as discussões sobre as violências na escola, marcadas pelo conflito com foco na construção das homossexualidades masculinas no contexto escolar. O segundo, ao articular gênero, sexualidade e educação fez brotar inúmeros questionamentos sobre esse espaço - os banheiros - de "alta densidade simbólica". O terceiro, ao veicular a pesquisa sobre os discursos produzidos em revistas e seus efeitos na constituição da subjetividade de mulheres brasileiras e portuguesas, possibilitou a discussão dos seguintes conceitos: a ordem do discurso (FOUCAULT, 2003), prática divisora (FOUCAULT, 2004), urgências históricas, dispositivo da sexualidade (FOUCAULT, 1997). As imagens da mulher Bela Adormecida e a da multiorgástica fizeram com que as mulheres reportassem às suas próprias histórias inserindo-as no contexto sócio-histórico-cultural macro e falassem sobre a sexualidade da mulher sob o prisma da anormalidade, frigidez, dificuldade em atingir o êxtase sexual, sexo e reprodução, performance no sexo, prazer sexual dentro e fora do casamento, virgindade, menopausa, sensualidade, erotismo, masturbação, disfunções sexuais, pudores, hipersexualização, intimidade. Outras autoras também têm os seus textos veiculados na referida publicação, mas apresentaram seus trabalhos na 28 . RA: Relações dialógicas interculturais: brinquedos e gênero, de Mônica Ledo Silvestri e Flávia de Oliveira Barreto (2008); Construindo a masculinidade hegemônica: acomodações e resistências a partir da apropriação de personagens de novelas por adolescentes das camadas populares, de Claudia Regina Santos Ribeiro e Vera Helena Ferraz de Siqueira (2008).

\section{5) $31^{\text {a }}$. RA: muitos fios a puxar}

Três pôsteres apresentados com temas dos mais instigantes: a) álbuns de mulheres negras; b) tendas da sexualidade e gênero; c) posturas de alunas mal comportadas.

Os trabalhos foram em número de 11 e os temas são os que seguem: 1) organização e distribuição de espaços, objetos e atividades no cotidiano da Educação Infantil; 2) politização do feminino e da maternidade nas revistas Pais \& Filhos de 1968 a 2004; 3) Gênero e livros didáticos das décadas de 20 a 50 em MG; 4) formação docente para a abordagem da sexualidade no ambiente escolar; 5) os manuais de conduta e a escrita feminina no início do século XX; 6) questões de gênero e diversidade sexual e o trabalho com literatura infantil; 7) narrativas de jovens mulheres em diários autobiográficos; 8) sexualidade na escola mediada pela literatura; 9) pedagogia queer; 10) como meninos e meninas em situação de rua vivem suas relações familiares; 11) linguagem empregada para designar a genitália e práticas sexuais na cultura brasileira. 
Tantos fios a puxar! A escolha recaiu sobre o trabalho que se debruça sobre o referencial teórico de Bourdieu com o argumento de que este autor também foi citado algumas vezes nos trabalhos analisados. O título do trabalho é: Roteiros de gênero: a pedagogia organizacional e visual gendrada no cotidiano da Educação Infantil, de autoria de Maria Eulina Pessoa de Carvalho, Eliana Célia Ismael da Costa e Rosemary Alves de Melo (2008). O primeiro conceito veiculado é o de habitus (BOURDIEU, 1986, 1977; BORDIEU e PASSERON, 1975). As autoras entendem que a organização dos espaços, objetos, rotinas e atividades no cotidiano dessas Instituições de Educação Infantil constituem roteiros prescritivos de habitus e relações de gênero; para tanto discutem também a reprodução da dominação masculina (BOURDIEU, 1999) e tantos outros aspectos da pedagogia organizacional e visual gendrada.

\section{4) Legitimação e consolidação do GT 23 nas últimas cinco reuniões anuais da Anped (2009/32 a 2013/36 . RAs)}

Dos $86^{9}$ trabalhos apresentados nos últimos cinco anos no GT 23, observamos recorrências, dissonâncias, proximidades, distanciamentos de temas, abordagens metodológicas e teorizações diversas, revelando um campo de conhecimento com encaminhamentos teórico-metodológicos plurais. Louro (2007), ao analisar as correlações entre afinidade política e tensões teóricometodológicas no campo dos estudos de gênero, sexualidade e educação, destaca a pluralidade dos distintos modos de conhecer, de conceber gênero e sexualidade e as múltiplas e diversas possibilidades metodológicas adotadas em pesquisa nesses campos teóricos.

Esta multiplicidade está presente nos inúmeros trabalhos apresentados no GT 23, evidenciando que gênero e sexualidade encontram terreno fértil no campo da educação. Além disso, esses estudos são frequentes no diálogo com outros campos disciplinares: Estudos de Gênero, Estudos Culturais, sociologia, antropologia, cinema, estudos da infância, psicanálise, interface entre gênero, etnia/ raça e classe social, entre muitos outros. O 'borramento' de fronteiras teóricas e disciplinares são marcas que unem os vários estudos apresentados nos últimos anos.

Nesses últimos cinco anos vivemos um período de consolidação e legitimação do GT, tanto pelo reconhecimento da Associação quanto por sua efetivação como espaço profícuo de encontros, discussões, estudos, trocas teóricas e afetivas, espaço de muitas discussões e ideias que nos instigaram a produzir coletivamente, em grupos de estudos e de pesquisa em várias regiões do Brasil. Diante de toda a riqueza de conceitos, proposições e novas formas de pensar trazidas pelos textos, passaremos, nessa última parte, a refletir com eles, sobretudo como parte de uma rede de conhecimento que se caracteriza pela multiplicidade, pela complexidade e pela provisoriedade que nos marcam como pesquisadoras e pesquisadores nos campos dos conhecimentos teóricos e políticos em sexualidades, gênero e educação.

Desse período, dois trabalhos, dentre os apresentados no GT 23, se destacam por analisar os discutidos no GT. Um deles é de Márcia Ondina Vieira Ferreira e de Georgina Helena Lima Nunes (2010).

9 Os trabalhos orais somaram 76 e os pôsteres, dez. 
Nele, as autoras buscaram reconstruir o panorama da produção sobre gênero e sexualidade nas reuniões da Anped. Ganhou destaque, dentre os vários GTs, o 23, como espaço privilegiado e agregador das discussões que envolviam gênero, sexualidade e educação. $O$ outro, de autoria de José Licínio Backes e Ruth Pavan (2011), buscou analisar, nos textos apresentados, especificamente no GT 23, como os conceitos de identidade, diferença e cultura foram discutidos nos anos de 2005 a 2009. Os/as autores/as ressaltaram que os trabalhos apresentam resultados ricos e relevantes que incitam a novos estudos, bem como destacaram a importância do espaço privilegiado do GT em uma associação que discute e prioriza a educação.

A educação, segundo a maioria dos trabalhos, é concebida de forma ampla, para além da desenvolvida em instâncias educativas como família e escola. Este pressuposto é compartilhado por pesquisas que problematizam outros espaços educativos constituidores de identidades e de produção de subjetividade mediante pedagogias culturais e pedagogias da sexualidade e de gênero (LOURO, 2000). Para esses estudos, a educação é um processo amplo. Meyer (2009) problematiza:

[...] o conjunto de processos através do qual indivíduos são transformados ou se transformam em sujeitos de uma cultura. Tornar-se sujeito de uma cultura envolve um complexo de forças e de processos de aprendizagem que hoje deriva de uma infinidade de instituições e "lugares pedagógicos" para além da família, da igreja e da escola, e engloba uma ampla e variada gama de processos educativos, incluindo aqueles que são chamados em outras teorizações de "socialização". (MEYER, 2009, p. 222)

Segundo a autora, somos sujeitos culturais e nos tornamos sujeitos da cultura em meio a inúmeros processos de aprendizagem e de interação constante com a cultura. Os trabalhos apresentados no GT, que investem na discussão das mais diversas instituições educativas, lugares e espaços pedagógicos, bem como em diversas pedagogias culturais, procuraram investigar: 1) o currículo do Orkut; 2) o currículo de masculinidade nos estádios de futebol; 3 ) as pedagogias do cinema, ao vincular o amor romântico em filmes destinados ao público da infância; 4) a análise da revista Pais \& Filhos e os imperativos da maternidade e paternidade responsáveis; 5) a subjetividade da mãe naturalista e a produção da maternidade ecológica; 6) o discurso sobre o corpo idoso, em caderno de saúde em jornal de grande circulação, visando a entender os argumentos a capturar pessoas idosas a terem corpos saudáveis e em movimento. A escola também é amplamente discutida como espaço específico de produção de identidades e subjetividades. Dentre os estudos apresentados, alguns a destacam como locus de produção de identidade e de subjetivação de alunos com orientação homossexual. Outro estudo a ser destacado é o de Neil Franco e Maria Veranilda Soares Mota (2010), no qual se analisam as histórias de vida e as trajetórias de formação escolar e acadêmica de professoras trans e de professores/as homossexuais e lésbicas, destacando os processos de sua exclusão da vivência no espaço da escolarização e das maneiras de se constituir como docentes, tendo que se subjetivar em espaços escolares heteronormativos e excludentes.

Outro aspecto que une os vários trabalhos apresentados nos últimos anos refere-se ao entendimento da sexualidade no campo político, como afirma Louro (2000). Para a autora, a "sexualidade não 
é apenas uma questão pessoal, mas é social e política" e "é aprendida" (p. 61). Estas questões são compartilhadas pelas pesquisas e trabalhos apresentados, independente da diversidade de suas escolhas teórico-metodológicas. Os estudos apresentados se interessaram politicamente para combater a homofobia, o sexismo, a misoginia e a LGBTfobia, entre quaisquer outras formas de violência, segregação, iniquidade e infração dos direitos humanos dentro e fora da escola, e estão comprometidos contra todas elas.

Dentre todos os trabalhos que se posicionam politicamente diante dessas questões, citamos alguns que tematizam: 1) a heterossexualização compulsória; 2) a discussão sobre o silêncio, a segregação e exclusão de corpos, gêneros e sexualidades que não correspondem à norma heterossexual; 3) a problematização de silêncios, negações e violações dos direitos humanos na escola em discursos de agentes públicos; 4) as experiências de preconceito contra professoras travestis e transexuais no exercício da docência; 5) a homofobia, a transfobia e a lesbofobia nas relações estabelecidas entre escola e famílias homoafetivas.

Os públicos investigados nos trabalhos apresentados também são plurais: crianças, adolescentes e jovens, adultos, idosos/as. Poucos estudos, porém, priorizaram pesquisas com crianças, buscando ouvir suas vozes e perceber que elas são sujeitos produtores de cultura. Dentre os trabalhos apresentados, destacam-se dois. O primeiro, de Gabriela Silveira Meireles (2009), analisou as relações de gênero na Educação Infantil de crianças de quatro a cinco anos de idade. A autora, mediante observação participante e entrevistas com crianças, buscou evidenciar que elas aprendem a se situar diante das concepções do que é ser menina e ser menino de acordo com o que espera a instituição educativa. Analisa como as crianças buscam se fixar em lugares que para elas já foram definidos culturalmente e também procuram se libertar desse jogo binário que as aprisiona e as impede de circular entre os opostos. O segundo trabalho é o de Constantina Xavier Filha (2011), que analisou as representações de gênero de crianças, estudantes do $5^{\circ}$ ano no Ensino Fundamental, de uma escola pública. A partir das discussões sobre um livro infantil, a autora discutiu com as crianças sobre gênero, provocando novas formas de pensar sobre o assunto. Dessas discussões, nasceram novas metodologias e a produção de um filme de animação.

A discussão sobre a adolescência e a juventude também ganhou destaque entre os trabalhos apresentados: 1) constituição identitária de jovens da periferia; 2) gravidez na adolescência nas vozes das jovens/adolescentes e seus processos de subjetivação; 3) masculinidades de alunos estudantes da EJA e seus processos de escolarização; 4) juventude e processos de escolarização; 5) gênero, raça, juventude e fracasso escolar; 5) escolarização, gênero e vulnerabilidade social nas narrativas juvenis de estudantes da EJA; 6) adolescentes e constituição de masculinidades na periferia. Percebemos, em alguns deles, a articulação entre gênero e escolarização. Isto nos leva a refletir acerca dos processos avaliativos e, sobretudo, a entender como os/as adolescentes se constituem e são constituídos nos processos educativos e de escolarização na escola.

Políticas públicas constituíram alvo de discussão e de crítica por parte de algumas pesquisas: 1) o programa Mulheres da Paz e os processos de governamentalidade da mulher-mãe; 2) a Infância 
Feliz e o envolvimento de mulheres como cuidadoras, educadoras e como principais responsáveis pelo cuidado pela prole; 3) a Primeira Infância Melhor, cuja centralidade está na infância, e os processos pelos quais se subjetiva a figura feminina para exercer o cuidado sobre a criança e garantir-lhe a sobrevivência; 4) a formação docente e, nesse segmento, o curso de formação continuada GDE - Gênero e Diversidade na Escola -, além da possibilidade de discutir o currículo do curso em várias regiões do país e seu alcance educativo na 'formação' da docência.

A formação docente em torno de temas como sexualidade, gênero e diversidades também ganhou destaque em estudos de caso e nas análises de currículos de cursos de graduação de formação do/a pedagogo/a. A formação inicial é analisada nos estudos de Roney Polato de Castro e Anderson Ferrari (2011), que destacam uma disciplina no curso de pedagogia. As trajetórias das discussões, dos saberes-poderes instituídos no âmbito da disciplina optativa são descritos pelos autores, os quais, ao mesmo tempo em que narram a experiência, se subjetivam como pesquisadores e professores. O currículo de alguns cursos de pedagogia, voltados à análise da presença, da ausência ou dos silenciamentos das temáticas de gênero e sexualidade também ganharam destaque, além dos que analisaram as experiências de formação continuada.

A docência e as mais diversas práticas pedagógicas também ganharam relevo nas tramas das várias pesquisas apresentadas no GT 23. A docência de professoras travestis, transexuais e de professores/ as homossexuais e lésbicas foi analisada observando especialmente os efeitos dessas vivências em espaços heteronormativos, como já se destacou anteriormente. Outras práticas e vivências na docência destacam a presença de professor-homem na Educação Infantil; a visibilidade da sexualidade do/a docente homossexual na escola; as práticas de educação física como espaço de discussão e/ou de ensino da norma heteronormativa nas práticas desportivas; a discussão de práticas que visam a garantir espaços de diferenciação em jogos e brincadeiras de meninos e meninas na Educação Infantil; as discussões sobre as aulas de biologia e de entendimento de como o corpo é priorizado nessa área de conhecimento. A Educação Infantil também foi alvo de discussão e estudos, em especial com a problematização das práticas pedagógicas das docentes com crianças pequenas. Destaca-se o estudo de Cláudia Maria Ribeiro (2012), que analisa as narrativas de professoras dessa etapa em momento de formação continuada, acerca das expressões de sexualidade e de gênero das crianças. Argumenta que nos labirintos da Educação Infantil sexualidade e gênero estão emaranhados nas práticas cotidianas, mas que nem sempre os/as profissionais que lá atuam conseguem dialogar abertamente e tratar das possibilidades de incluir as questões de sexualidade, gênero e diversidades nos currículos.

A educação sexual é analisada mais detidamente em dois trabalhos. Um deles analisa o histórico da educação sexual na primeira metade do século XX, de autoria de Lucélia de Moraes Braga Bassalo (2010); o outro, escrito por Maria Rita Assis César (2010), discute educação sexual e governamento dos corpos. A autora problematiza historicamente como a questão sexualidade desperta o interesse das instituições até chegar à escola nos dias de hoje com o controle dos corpos e com o governamento da sexualidade. 
Dos trabalhos apresentados/selecionados no GT 23, nos últimos cinco anos de sua existência, percebemos uma diversidade de abordagens metodológicas: etnografia, entrevista semiestruturada, entrevista narrativa, observação participante, análise documental, questionário, grupo focal, pesquisa com crianças, estudo de caso, cartografia, pesquisa-ação, pesquisa teórica. As fontes de estudos também foram múltiplas: narrativas orais, política pública, livro paradidático, livro didático, o Parâmetro Curricular Nacional - em especial o de Orientação Sexual -, manuais médicos, músicas, revistas, documentos oficiais e de divulgação de programas e projetos governamentais, dentre outros.

Na utilização das várias possibilidades metodológicas, foram elaboradas outras maneiras de utilizar fontes e estratégias de pesquisa, com vistas a estimular a criatividade e a recriar as técnicas de pesquisa convencionais. Esta opção se deu devido à articulação com as teorizações escolhidas. Em sua grande maioria, as abordagens teóricas dos trabalhos apresentados nos últimos cinco anos no GT podem ser descritas como pós-críticas ${ }^{10}$. Meyer e Paraíso (2012) destacam que o rótulo de 'pós' traz em seu bojo as teorizações do pós-estruturalismo, pós-modernismo, pós-gênero, pensamento da diferença, Estudos Culturais, Estudos de Gênero, Estudos étnicos e raciais, Estudos Queer, dentre outros. Experimentamos formas éticas e estéticas de fazer pesquisa, de descrever experiências, de buscar problematizar algo que é socialmente naturalizado, de tencionar o que está sacralizado pelas normas socialmente aceitas como 'verdades únicas'. As pesquisas apresentadas no GT 23 acenam para novas formas de se lidar com a produção do saber-poder-verdade, de nos colocar em xeque diante do novo, da adoção de diversas formas de pesquisar, de aprender junto e de nos subjetivar com nossas pautas de estudos, que são políticas e comprometidas com novas possibilidades de ser, conhecer e pensar novas realidades e possibilidades. O esforço em construir novas metodologias se deve ao fato de que "sabemos que o modo como fazemos nossas pesquisas vai depender dos questionamentos que fazemos, das interrogações que nos movem e dos problemas que formulamos" (PARAÍSO, 2012, p. 24). As teorizações dos estudos e ensaios apresentados fundamentaram-se especialmente em Foucault, Derrida e Guatarri, Nietzsche, Scott, Louro, Butler, Preciado, Connell, Borrillo, Lacan.

A opção pelas teorizações pós-críticas nos estudos apresentados no GT 23 instigam a pensar e a repensar o fazer pesquisa ${ }^{11}$. Dentre as várias discussões apontadas, destacaram-se: 1) questionar e evidenciar a linguagem como produção de sentidos; 2) suspeitar das metanarrativas; 3) problematizar e explorar a indeterminação, a ambiguidade, a instabilidade, a multiplicidade e a provisoriedade dos sentidos e significados; 4) problematizar a cultura e perceber que ela é fruto de construções discursivas, de poder e que, portanto, não é imutável; 5) priorizar o local e o particular em detrimento do global, universal; 6) questionar o que é dado como natural, correto, normal; 7) rejeitar e problematizar noções essencialistas e universais de homem/mulher, entre outras.

10 Há poucos trabalhos que se posicionam teoricamente nas pesquisas críticas, com conceitos de reprodução social, capital cultural, entre outros, especialmente com estudos fundamentados em Bourdieu, Moscovici, Thompson. No entanto, apesar dessa opção teórica, utilizam-se conjuntamente teorias como as de Louro, Butler, Foucault.

11 Questões apontadas em estudos de teóricas/os que se utilizam das teorias pós-críticas em seus estudos, especialmente Louro (1997, 2000, 2001, 2007); Meyer (2003, 2012); Paraíso (2012) Silva (2003). 
Os conceitos de sexualidade e gênero também são citados e destacam as teorizações utilizadas por seus autores e autoras. O conceito de sexualidade como dispositivo histórico, analisado por Foucault (1997), é quase que unânime nos trabalhos apresentados nos últimos anos no GT, mesmo para os que adotam perspectivas teórico-críticas diferentes das do pós-estruturalismo. Já na opção pelo gênero, há divergências em torno do conceito, em especial entre os trabalhos que adotam as teorizações dos Estudos Queer. Os estudos apresentados, ao utilizar o conceito de gênero, destacam, sobretudo, as teorizações de quatro autoras: Scott, Louro, Meyer e Butler.

O conceito de gênero é oriundo dos movimentos sociais feministas. Segundo Louro (1997), é através das feministas anglo-saxãs que gender passou a ser usado como distinto de sex e, sobretudo, para diferenciar do objeto das pautas dos movimentos feministas que priorizavam a 'mulher' como objeto de lutas políticas. Ainda segundo a autora, é na década de 1980 que o conceito de gênero passa a ser utilizado no Brasil como ferramenta teórico-política nos estudos da academia, questionando o determinismo biológico e a essencialização do sujeito.

Na década de 1990, uma importante contribuição teórica foi a tradução e publicação no Brasil, por Guacira Lopes Louro, do texto de Joan Scott (1995) Gênero: uma categoria útil de análise histórica. O gênero pode ser compreendido como "elemento constitutivo de relações sociais baseadas nas diferenças percebidas entre os sexos" e como "uma forma primária de dar significado às relações de poder" (SCOTT, 1995, p. 86). Para a autora, o conceito passou a ser entendido como elemento constitutivo das relações sociais baseadas nas diferenças percebidas entre os sexos e também como uma forma de dar significado às relações de poder. Em síntese, o gênero foi tomado como categoria relacional; como construção social, cultural e histórica e como categoria analítica. Temos inúmeros trabalhos apresentados no GT 23 que compartilham desses pressupostos e continuam a utilizar as teorizações da autora como principal base de trabalho. Outros articulam esses conceitos com os da autora Guacira Lopes Louro.

Louro $(1997,2000)$ discute o conceito de gênero na articulação entre os estudos feministas e o pósestruturalismo, possibilitando repensá-lo nas relações de poder e nas formas de ressignificação da linguagem. Para ela, gênero é:

construção social feita sobre diferenças sexuais. Gênero refere-se, portanto, ao modo como as chamadas "diferenças sexuais" são representadas ou valorizadas; refere-se àquilo que se diz ou se pensa sobre tais diferenças, no âmbito de uma dada sociedade, num determinado grupo, em determinado contexto. (LOURO, 2000, p. 26)

A autora argumenta que não analisa o conceito ligado ao desempenho de papéis (masculino e feminino), mas como constitutivo da produção de identidades (múltiplas, instáveis e plurais) de mulheres e homens no interior de práticas sociais e culturais. Os estudos da autora são amplamente discutidos e problematizados em quase todas as pesquisas e ensaios apresentados nos últimos anos no GT 23.

Na linha dos estudos de Louro, os estudos de Meyer (2003, 2009, 2012) também contribuem sobremaneira nas discussões apresentadas nos trabalhos. A autora argumenta que gênero continua 
a ser uma ferramenta conceitual, política e pedagógica central para nossas pesquisas. Destaca que o conceito nos leva a pensar que nada é 'natural' e que aponta para a noção de que ao longo da vida nos constituímos como homens e mulheres em processos inacabados e não-lineares. $\mathrm{O}$ conceito ainda revela que "existem muitas e conflitantes formas de definir e viver a feminilidade e a masculinidade" (2003, p. 17). A autora também ressalta que tomar o conceito de gênero como um elemento organizador da cultura possibilita examinar os diferentes modos pelos quais o gênero opera na cultura e no social. Assim, gênero "engloba todos os processos pelos quais a cultura constrói e distingue corpos e sujeitos femininos e masculinos” (MEYER, 2012, p. 51).

Pensando o gênero como elemento organizador da cultura e como aspecto relacional, alguns trabalhos apresentados no GT 23 destacam como prioridade analisar a constituição do feminino com a análise da narrativa de professoras mulheres, jovens grávidas, adolescentes estudantes da EJA. Outros estudos, no entanto, pretenderam estudar a masculinidade ao entender os processos de subjetivação de professores-homens na Educação Infantil, na constituição da masculinidade na dança, na constituição de masculinidades juvenis na periferia, na presença de homens nos cargos de gestão das escolas, nos processos de masculinidade, fracasso e escolarização. Nesses estudos, evidenciamos que o conceito de gênero é utilizado como categoria de análise para entender os processos relacionais de constituição de masculinidades e feminilidades. $\mathrm{O}$ conceito de masculinidade hegemônica de Connell (1995) é articulado ao de gênero, provocando vigorosas discussões sobre os processos culturais, relacionais e históricos da constituição dos sujeitos, em muitos dos trabalhos apresentados.

Os estudos que se utilizam do conceito gênero, apresentados no GT 23 nos últimos cinco anos, também chamam a atenção sobre um ponto enfatizado por Nicholson (2000), que é o determinismo biológico presente em algumas discussões sobre gênero, sobretudo para quem considera o 'sexo' algo alheio à cultura. Ou seja, o conceito de gênero estaria ancorado em um corpo sexuado. Esta visão limita o entendimento das diferenças entre as mulheres, as diferenças entre homens e as diferenças em relação a quem pode ser considerado homem ou mulher (NICHOLSON, 2000). Louro (2007) discute as ponderações descritas por Nicholson, estimulando-nos a refletir que a "construção social se faz sobre um corpo significa colocar em questão a existência de um corpo a priori, quer dizer, um corpo que existiria antes ou fora da cultura" (p. 209). Seria possível, assim, entender que a designação de "gênero não é, simplesmente, a descrição de um corpo, mas aquilo que efetivamente faz existir esse corpo - em outras palavras, o corpo só se tornaria inteligível no âmbito da cultura e da linguagem" (p. 209).

Louro, a partir das perspectivas construcionistas, questiona o essencialismo e o determinismo biológico e nos leva a pensar o gênero como construção social e cultural. A autora amplia essas discussões ao introduzir os estudos de Judith Butler no Brasil, especificamente nas análises da educação, quando publica a Teoria Queer: uma política pós-identitária para a educação (2001), e o livro Um corpo estranho (2004). Butler (2003) enfatiza a necessidade de romper com o sistema binário que corrobora a relação entre gênero e sexo, ao afirmar que o primeiro é determinado pelo segundo. Assinala que o gênero não pode ser entendido apenas como algo que se consolida 
mediante a heterossexualidade normativa mediante atos performativos. Alguns últimos trabalhos apresentados no GT questionam veementemente o conceito de gênero comumente adotado e utilizam o conceito de Butler para questionar os binarismos que se consolidaram ao tratar de gênero em alguns estudos.

O trabalho de Denise da Silva Braga (2011) é enfático em afirmar que o conceito de gênero adotado na maioria dos trabalhos parte da discussão do corpo biológico e do binarismo de gênero masculino e feminino, na perspectiva da heteronormatividade. Questiona como as vidas na fronteira, especialmente para as pessoas trans, não são visibilizadas e legitimadas pelo conceito de gênero vigente. Utiliza Butler $(2003,2004)$ para ‘desfazer o gênero' e pensá-lo como produto de processos performativos, ou seja, resultante da repetição constante das normas que regulam corpos, sexos e gêneros. Para Braga, gênero é algo pensado como uma imitação persistente, que passa como real e, no entanto, é a própria repetição da norma que ocasiona a sua ressignificação e a sua proliferação para além da estrutura binária (masculino/feminino).

Essas discussões ainda são incipientes nos trabalhos do GT, mas acenam para reflexões e problematizações vindouras; dentre elas, a de pensarmos se o conceito de gênero não traz à discussão a desconstrução do binarismo do masculino e feminino de forma relacional. Entre outras questões: Como repensar conceitualmente gênero? Ressignificá-lo? Construí-lo e desconstruí-lo em nossos estudos?

Trata-se de temas férteis sobre os quais é preciso refletir nos próximos dez anos do GT. Quais outros temas/conceitos serão emergentes? Silenciados? Quais serão (re)significados? Como pensar a provisoriedade dos saberes? Como escapar das conclusões iluministas em nossos estudos (LOURO, 2007)? Como navegar pela ars erótica (FOUCAULT, 1997)?

Enfim... não tem fim! Muito há que se produzir e aventurar nesses mares revoltos das incertezas e dos inusitados. Que venham muitos anos radiantes para o nosso pulsante... potente... GT 23.

\section{REFERÊNCIAS:}

BACKES, José Licínio; PAVAN, Ruth. A produtividade dos conceitos de identidade, diferença e cultura nos estudos de gênero articulada com as epistemologias. In: 34 ${ }^{\mathrm{a}}$. ANPEd: Natal, 2011.

BASSALO, Lucélia de Moraes Braga. A educação sexual na primeira metade do seculo XX no Brasil. In: 33ä. ANPEd: Caxambu, 2010.

BOURDIEU, Pierre e PASSERON, J. C. A reprodução: elementos para uma teoria do sistema de ensino. Rio de Janeiro: Francisco Alves, 1975.

BOURDIEU, Pierre. A dominação masculina. Rio de Janeiro: Bertrand Brasil, 1999.

BOURDIEU, Pierre. Cultural Reproduction and Social Reproduction. In: KARABEL, J., HALSEY, A. (Eds.). Power and ideology in Education. (p. 487-511). New York: Oxford University Press, 
1977.

BOURDIEU, Pierre. The forms of Capital. In: RICHARDSON, J.G. (Ed.). Handbook of theory and research for the Sociology of Education. New York: Greenwoods Press, 1986.

BRAGA, Denise da Silva. A experiência transexual: estigma, estereótipo e desqualificação social no intramuros da escola. In: 34‥ ANPEd: Natal, 2011.

BUTLER, Judith. Deshacer el gênero. Barcelona: Ediciones Paidós, 2004.

BUTLER, Judith. Problemas de gênero. Feminismo e subversão da identidade. Rio de Janeiro: Civilização Brasileira, 2003.

CAMPOS, Miriam Piber. Identidades “anormais": a (des)construção dos corpos “deficientes". In: 29a. ANPED: Caxambu, 2006.

CASTRO, Roney Polato de; FERRARI, Anderson. "Nossa! Eu nunca tinha parado pra pensar nisso!" Gênero, sexualidade e formação docente. In: 34ㄹa . ANPEd: Natal, 2011.

CÉSAR, Maria Rita de Assis. Governando corpos e sexualidades na escola. In: 33ạ . ANPEd: Caxambu, 2010.

COHEN, Jeffrey Jerome. A cultura dos monstros: sete teses. In: SILVA, Tomaz Tadeu da (Org.). Pedagogia dos monstros: os prazeres e os perigos da confusão de fronteiras. Belo Horizonte: Autêntica, p. 23-60, 2000.

CONNELL, R. W. Políticas da Masculinidade. Educação e Realidade, Porto Alegre, v. 20 (2), p. 185-206, jul./dez., 1995.

DERRIDA, Jacques. Posições. Belo Horizonte: Autêntica, 2001.

FERNANDES, Wânia Ribeiro; SIQUEIRA, Vera Helena Ferraz. Cinema e Relações de Gênero: ouvindo mulheres idosas. In: 29 . ANPED: Caxambu, 2006.

FERRARI, Anderson. A "bicha banheirão" e o "homossexual militante": grupos gays, educação e a construção do sujeito homossexual. In: 29 ${ }^{a}$ ANPED: Caxambu, 2006.

FERREIRA, Márcia Ondina Vieira; NUNES, Georgina Helena Lima. Panorama da produção sobre gênero e sexualidades apresentada nas reuniões da ANPEd (2000-2006). In: 33 ${ }^{a}$. ANPEd: Caxambu, 2010.

FOUCAULT, Michel. A ética do cuidado de si como prática de liberdade. In: FOUCAULT, Michel. Ética, sexualidade, política. Coleção Ditos \& Escritos (Volume V). Rio de Janeiro: Forense Universitária, 2004.

FOUCAULT, Michel. Arqueologia do saber. Rio de Janeiro: Forense Universitária, 4. ed., 1995. FOUCAULT, Michel. História da Sexualidade I: a vontade de saber. 12. ed. Rio de Janeiro: Graal, 1997.

FOUCAULT, Michel. A ordem do discurso. 9. ed. São Paulo: Loyola, 2003.

FRANCO, Neil; MOTA, Maria Veranilda Soares. A visibilidade da sexualidade do/a docente homossexual na escola. In: 33ㄹ. ANPEd: Caxambu, 2010.

FURLANI, Jimena. Sexos, sexualidades e gêneros - monstruosidades no currículo da Educação Sexual. In: 28 ${ }^{a}$. ANPED: Caxambu, 2005.

LIBÓRIO, Renata Maria Coimbra; CAMARGO, Luciene dos Santos. A violência sexual contra crianças e adolescentes na perspectiva de profissionais da educação das escolas públicas municipais de Presidente Prudente. In: 29 ${ }^{a}$. ANPED: Caxambu, 2006. 
LOURO, Guacira Lopes. Currículo, género e sexualidade. Porto: Porto Editora, 2000.

LOURO, Guacira Lopes. Gênero, sexualidade e educação: das afinidades políticas às tensões teórico-metodológicas. In Educação em Revista. Belo Horizonte, n. 46, dez., 2007.

LOURO, Guacira Lopes. Gênero, sexualidade e educação: uma perspectiva pós-estruturalista. Petrópolis, RJ: Vozes, 1997.

LOURO, Guacira Lopes. Teoria queer: uma política pós-identitária para a Educação. Revista Estudos Feministas, v. 9, n. 2, 2001.

LOURO, Guacira Lopes. Um corpo estranho. Belo Horizonte: Autêntica, 2004.

MEIRELES, Gabriela Silveira. O que dizem as crianças sobre meninos e meninas? In: 32 a . ANPEd: Caxambu, 2009.

MEYER, Dagmar E. Corpo, violência e educação: uma abordagem de gênero. In: JUNQUEIRA, Rogério (Org.). Diversidade sexual na educação: problematização sobre a homofobia nas escolas. Brasília: MEC/Secad, UNESCO, 2009.

MEYER, Dagmar E. Gênero e educação: teoria e política. In: LOURO, Guacira; NECKEL, Jane; GOELLNER, Silvana (Orgs.). Corpo, gênero e sexualidade: um debate contemporâneo. Petrópolis: Vozes, 2003.

MEYER, Dagmar Estermann; PARAÍSO, Marlucy Alves (Orgs.). Metodologias de pesquisas póscríticas em educação. Belo Horizonte: Mazza, 2012.

NICHOLSON, Linda. Interpretando o gênero. In: Estudos Feministas, Florianópolis: UFSC, v. 8, n. 2, p. 09-41, 2000.

ORTEGA, Francisco. Da ascese a bio-ascese: ou do corpo submetido à submissão do corpo. In: RAGO, Margareth; ORLANDI, Luiz B. Lacerda; VEIGA-NETO, Alfredo (Orgs.). Imagens de Foucault e Deleuze: ressonâncias nietzschianas. Rio de Janeiro: DP\&A, 2002, p. 139-173.

PARAÍSO, Marlucy Alves. Metodologias de pesquisas pós-críticas em educação e currículo. In MEYER, Dagmar Estermann; PARAÍSO, Marlucy Alves (Orgs.). Metodologias de pesquisas póscríticas em educação. Belo Horizonte: Mazza, 2012.

PASSETTI, Edson. Éticas dos amigos: invenções libertárias da vida. São Paulo: Imaginário, 2003. RABINOW, Paul. \& DREYFUS, Hubert. Michel Foucault: Uma trajetória filosófica para além do estruturalismo e da hermenêutica (V. P. Carrero, trad.). Rio de Janeiro: Forense Universitária. 1995. RIBEIRO, Cláudia Maria e SOUZA, Ila Maria Silva. Tecendo gênero e diversidade sexual nas redes de proteção. Lavras, MG: Editora UFLA. 2008.

RIBEIRO, Cláudia Maria. No labirinto da educação infantil as falas de educadoras. In: 35a . ANPEd: Porto de Galinhas, 2012.

SANTOS, Luís Henrique Sacchi; OLIVEIRA, Dora Lúcia Leidens Correa. Gênero e risco de HIV/ Aids nas campanhas de educação em saúde através da mídia. In: 29ª ANPED: Caxambu, 2006. SCOTT, Joan W. Gênero: uma categoria útil de análise histórica. In: Educação \& Realidade, Porto Alegre, v. 20, n. 2, jul/dez 1995.

SILVA, Tomaz Tadeu da (Org.). Identidade e diferença. A perspectiva dos Estudos Culturais. 2. ed. Petrópolis: Vozes, 2003.

XAVIER FILHA, Constantina. A menina e o menino que brincavam de ser... Representações de gênero em pesquisa com crianças. In: 34ạ . ANPEd: Natal, 2011. 